\title{
Contagem de plaquetas e caracterização clínica de úlceras de perna anticardiolipinas positivas
}

\section{Platelet count and clinical profile of anticardiolipin positive leg ulcers}

Thelma Laroka Skare"; Carmen Autralia Paredes Marcondes Ribas²; Osvaldo Malafaia, ECbC-PR²; Jurandir Marcondes Ribas Filho, TCBC-PR²; Paulo Afonso Nunes Nassif, TCBC-PR²; Marcelo Mazza do Nascimento ${ }^{2}$; Jan Pawel Andrade Pachnicki ${ }^{1}$

\section{R E S U M O}

\begin{abstract}
Objetivo: Estudar a prevalência de anticorpos anticardiolipinas em pacientes com úlceras venosas, diabéticas e arteriais e verificar se a contagem de plaquetas, antecedentes obstétricos e de trombose venosa profunda e achados de livedo reticularis ao exame físico servem como marcadores para os casos positivos. Métodos: Estudaram-se 151 pacientes com úlcera de perna (81 com úlceras venosas, 50 com úlceras diabéticas e 20 com úlceras arteriais) e 150 controles. Pesquisou-se, nos dois grupos, a presença de anticorpos anticardiolipina IgG e $\operatorname{lgM}$ e contagem de plaquetas. No grupo úlcera foram coletados dados de antecedentes de trombose venosa profunda e de abortamentos e os pacientes foram examinados para presença de livedo reticularis. Os dados obtidos foram agrupados em tabelas de frequência e contingência utilizando-se dos testes de Fisher e qui-quadrado para variáveis nominais e de Mann-Whitney e Kruskall-Wallis para as numéricas. Adotou-se significância de 5\%. Resultados: Encontrou-se prevalência de anticorpos anticardiolipina de $7.2 \%(n=12)$ no grupo com úlceras e de $1.3 \%(n=2)$ no controle $(p=0.01)$. As úlceras de perna anticardiolipinas positivas não diferiram daquelas sem anticardiolipinas quanto ao gênero do paciente $(p=0.98)$ e história de trombose prévia $(p=0.69)$, abortamentos anteriores $(p=0.67)$ e contagens de plaquetas $(p=0.67)$. Só dois pacientes tinham livedo reticularis não permitindo inferências estatísticas a respeito deste dado. Conclusão: Existe aumento de prevalência de anticorpos anticardiolipinas nos portadores de úlceras de perna em relação à população geral. As características clínicas das úlceras anticardiolipinas positivas e a contagem de plaquetas não auxiliam na identificação desses pacientes.
\end{abstract}

Descritores: Úlcera de perna. Insuficiência venosa. Úlcera cutânea. Pé diabético. Anticorpo anticardiolipina.

\section{INTRODUÇÃO}

A síndrome do anticorpo antifosfolípide (SAF) é considerada a causa mais comum de trombofilia'. Ela é causada por um grupo de auto anticorpos dirigidos contra fosfolípides de carga negativa, dentre os quais se destacam a anticardiolipina (aCl) IgG, aCl IgM, o lúpus anticoagulante e a anti â-2 glicoproteina I' ${ }^{1}$. Esses anticorpos causam tromboses em vasos de todos os tamanhos, sejam eles arteriais ou venosos, o que determina o perfil de achados clínicos ${ }^{1,2}$. Os anticorpos aCls aparecem cinco vezes mais frequentemente que o lúpus anticoagulante e estão mais associados com tromboses arteriais ${ }^{3}$.

Essa síndrome pode aparecer de maneira isolada, forma essa conhecida como SAF primária, ou associada a outras doenças, principalmente as colagenoses, na chamada SAF secundária'. Na forma primária, abortamentos de repetição ocasionados por isquemia de vasos placentários são uma forma bastante comum de apresentação ${ }^{4}$. Na forma secundária, a doença mais frequentemente associada é o lúpus eritematoso sistêmico'.
Manifestações dermatológicas são encontradas em $49 \%$ dos pacientes com SAF sendo o sintoma inicial da doença em 30,5\% dos casos $^{5}$. A manifestação dermatológica mais comum é o livedo reticularis que foi encontrado em $25,5 \%$ dos indivíduos afetados de uma série de 200 pacientes com a forma primária e secundária ao LES $^{5}$. Outro achado cutâneo da SAF é a atrofia branca, associada ou não com vasculopatia livedoide ${ }^{6}$. Encontramse ainda úlceras de pernas, úlceras do tipo pioderma gangrenoso, acrocianose, fenômeno de Raynaud, tromboflebites superficiais, obstruções arteriais vasculares com isquemia (dedo azul) e lesões de anetoderma ${ }^{5}$.

Além de manifestações isquêmicas e cutâneas, plaquetopenia tem sido encontrada nessa entidade. Em um estudo de 1.000 pacientes com SAF, Cervera et al ${ }^{7}$ encontraram plaquetopenia em $22 \%$ dos casos. Não se conhece a causa exata da diminuição de plaquetas, mas uma explicação aceita é a de que é secundária ao consumo dessas células por ativação das mesmas pelos autoanticorpos - o que serviria como núcleo para formação de trombos ${ }^{3}$.

Trabalho realizado no Programa de Pós-Graduação em Princípios da Cirurgia do Hospital Universitário Evangélico de Curitiba/Faculdade Evangélica do Paraná, Curitiba, PR-BR.

1. Mestre do Programa de Pós-Graduação em Princípios da Cirurgia do Hospital Universitário Evangélico de Curitiba/Faculdade Evangélica do Paraná, Curitiba, PR-BR. 2. Doutor, Professor Permanente do Programa de Pós-Graduação em Princípios da Cirurgia do Hospital Universitário Evangélico de Curitiba/Faculdade Evangélica do Paraná, Curitiba, PR-BR. 
Anticorpos antifosfolípides, junto com outras trombofilias, têm sido detectados em pacientes com úlceras de perna associadas à insuficiência venosa, diabete mellito e em úlceras arteriais. Mackenzie et al ${ }^{8}$ estudando 115 pacientes com úlceras de pernas encontrou positividade para anticorpos anticardiolipina em $42,6 \%$ dos com úlceras venosas, em $43,3 \%$ nos com úlceras arteriais e $42,8 \%$ nos com úlceras mistas. Alagözlü et al ${ }^{9}$, ao analisar 70 pacientes com diabete melito tipo 2 (35 sem e 35 com úlceras), encontrou maior prevalência de anticorpos anticardiolipina IgG naqueles com ulcerações.

Neste trabalho procurou-se estabelecer a prevalência de anticorpos anticardiolipina na população local com úlceras de perna e verificar se a contagem de plaquetas, antecedentes anteriores de tromboses venosas e abortamento de repetições ou o achado de livedo reticularis ao exame físico identifica a presença desses autoanticorpos neste contexto.

\section{MÉTODOS}

Este estudo foi aprovado pelo Comitê de Ética em Pesquisa da Sociedade Evangélica Beneficente de Curitiba ( $n^{\circ}$. 2431-2008) e tendo sido obtido o consentimento livre e esclarecido de todos os seus participantes.

Estudaram-se 151 pacientes com úlcera de perna (81 de causa venosa, 50 de origem diabética e 30 de origem arterial), aqui identificados como grupo úlcera e admitidos no estudo por ordem de chegada à consulta do ambulatório de Cirurgia Vascular do Hospital Universitário Evangélico de Curitiba e 150 controles pareados para sexo e idade, identificados como grupo controle. Foram considerados elegíveis para o estudo pacientes de ambos os sexos com úlcera de perna em atividade por pelo menos seis semanas.

Para inclusão no grupo úlcera venosa, os pacientes deveriam ter varizes de membros inferiores, história de trombose venosa, edema vespertino, dermatite ocre e/ou lipoesclerodermatose. Para inclusão no grupo de úlcera diabética, deveriam ter história pregressa de diabete melito comprovada ou glicose de jejum acima de $126 \mathrm{mg} / \mathrm{dL}$ ou, ainda, glicemia $2 \mathrm{~h}$ pós-prandial ou randômica acima de $200 \mathrm{mg} / \mathrm{dL}^{10}$. Para inclusão no grupo de úlcera arterial, deveriam apresentar diminuição de pulsos periféricos ou razão $=0.7$ entre pressão sistólica de membro inferior e superior ${ }^{11}$.

Excluíram-se indivíduos em uso de medicamentos e drogas sabidamente implicados na positividade dos anticorpos antifosfolípides (anti-TNF-a, diuréticos tiazídicos, propranolol, clorpromazina, interferon $\odot$, amoxacilina, procainamida e cocaína) ${ }^{12}$; pacientes com doença neoplásica ou doença associada com a presença desses anticorpos; presença de outras formas de infecção, que não a em úlcera de perna e pacientes com a possibilidade de úlceras mistas que não permitissem a inclusão do paciente em um grupo definido, exceto pelos casos dos com úlceras diabéticas onde era permitida associação do componente arterial e neuropático.

Pacientes com úlceras de perna foram submetidos a questionário para obtenção de antecedentes de trombose venosa profunda e abortamentos e ao exame físico para constatação de livedo reticularis

Pacientes do grupo úlcera e grupo controle foram submetidos à coleta de sangue venoso para pesquisa de aCls IgG e IgM pelo método de Elisa (Euroimmun, Lübeck, Germany) seguindo-se a técnica recomendada pelo manufaturador para contagem de plaquetas que foi feita imediatamente após a coleta de maneira automatizada utilizando-se um analisador hematológico (Advia 120®, Bayer).

Os dados obtidos foram coletados em planilhas sendo submetidos a estudos por tabelas de frequência e contingência. Para cálculo de associação de dados nominais utilizou-se o teste de Fisher ou do qui-quadrado de acordo com a amostra analisada. Para cálculo de associação de dados contínuos utilizaram-se os teste de MannWhitney e Kruskall-Wallis. Para cálculo de correlação utilizou-se o teste de Spearmann. Os testes foram realizados com auxílio do software GraphPad Prism ${ }^{\circledR}$ adotando-se o nível de significância de 5\%.

\section{RESULTADOS}

No grupo úlcera existiam 76 pacientes do sexo feminino e 75 do masculino contra 99 do sexo feminino e 51 do sexo masculino no grupo controle ( $p=0.07$, qui-quadrado). A idade média dos pacientes do grupo úlcera era de $60.7 \pm 12.0$ anos e do controle de $61.2 \pm 9.9$ anos $(p=0,63$; Mann Whitney).

No grupo controle encontrou-se a presença de anticorpos anticardiolipina em níveis acima de $10 \mathrm{U} / \mathrm{mL}$ em dois (1.3\%) pacientes. Ambos tinham anticorpos do tipo IgG em baixos títulos (fracamente positivos): $17.8 \mathrm{GPL} / \mathrm{mL}$ e $15 \mathrm{GPL} / \mathrm{mL}$. No grupo úlcera as anticardiolipinas encontraram-se níveis acima de $10 \mathrm{U} / \mathrm{mL}$ em 12 pacientes $(7.2 \%)$ sendo os valores de aCl lgG entre 10.2 e $47.9 \mathrm{GPL} / \mathrm{mL}$ (média de $18.3 \pm 13.6 \mathrm{GPL} / \mathrm{mL}$ e os valores de aCl lgM entre $11.2 \mathrm{e}$ 65.7 MPL/mL (média de $33.1 \pm 21.9 \mathrm{MPL} / \mathrm{mL}$ ).

Comparando-se a positividade de anticorpos anticardiolipina entre a população controle e a do grupo úlcera obteve-se $\mathrm{p}=0.01$ (Fisher).

Nos pacientes do grupo úlcera e anticorpos anticardiolipinas positivos, um tinha úlcera arterial (4.7\% da amostra de pacientes com úlceras arteriais); seis úlcera venosa ( $7.5 \%$ dos pacientes com úlcera venosa) e cinco úlcera diabética ( $10 \%$ da amostra de pacientes com úlcera diabética). Comparando-se a positividade dos anticorpos entre grupo controle e úlceras venosas obteve-se $p=0.02$ (Fisher); entre controle e úlceras diabéticas, $\mathrm{p}=0,01$ (Fisher) e entre controle e úlceras arteriais, $\mathrm{p}=0.61$ (Fisher).

O número de plaquetas nos pacientes do grupo úlcera variou entre $51.000 / \mathrm{mm}^{3} \mathrm{e} 777.000 / \mathrm{mm}^{3}$ (média de $327.2 \pm 133.7$ ) e entre $103.000 / \mathrm{mm}^{3}$ e $490.000 / \mathrm{mm}^{3}$ (mé- 
dia de $262.0 \pm 76.11)$ no grupo controle. Comparando-se o número de plaquetas dos pacientes do grupo úlcera com grupo controle obteve-se $p<0.0001$ (Mann Whitney).

Analisando-se o número de plaquetas nos diferentes tipos de úlceras de perna observou-se valor médio de $302.6 \pm 111.9 \times 10^{3} / \mathrm{mm}^{3}$ para as úlceras venosas; de $327.1 \pm 123.1 \times 10^{3} / \mathrm{mm}^{3}$ para as diabéticas e de $431.7 \pm 192.2$ $X 10^{3} / \mathrm{mm}^{3}$ para as arteriais ( $p=0.007$; Kruskall Wallis). A comparação das contagens de plaquetas nos diferentes tipos de úlceras de perna encontra-se ilustrada na figura 1.

Estudando-se a contagem de plaquetas dentro do grupo úlcera nos pacientes anticardiolipina positivos e negativos observou-se que número médio nos positivos era de $328.5 \pm 135.2 \times 10^{3} / \mathrm{mm}^{3}$ ) e nos sem anticardiolipinas era de $313.6 \pm 120.7 \times 10^{3} / \mathrm{mm}^{3}$, com $\mathrm{p}=0.67$ (MannWhitney).

Quando os pacientes do grupo úlcera positivos para anticorpos anticardiolipinas foram comparados com aqueles com úlcera, mas negativos para esse auto-anticorpo quanto a antecedentes de trombose, abortamentos e presença de livedo reticularis ao exame físico, observaram-se os dados da tabela 1.

\section{DISCUSSÃO}

Trombofilias têm sido identificadas em pacientes com úlceras de pernas em frequência 30 vezes maior do que a encontrada na população em geral ${ }^{8}$. A identificação de uma trombofilia subjacente à úlcera de perna pode alterar a conduta tomada em relação ao seu tratamento, que é reconhecidamente difícil. Embora Mackenzie et $a^{\beta}$ não tenham reconhecido associação entre trombofilias em úlcera de perna e tempo de duração do processo mórbido, número de recorrência, área total da úlcera ou prevalência de sintomas dolorosos, a literatura mostra descrição de casos isolados nos quais a anticoagulação esteve associada com fechamento da ferida ${ }^{13-16}$.

Neste estudo encontrou-se aumento de anticorpos anticardiolipina na população com úlcera de pernas embora os valores absolutos obtidos sejam mais baixos do que os achados na literatura. Tal fato pode ser explicado em termos de diferenças genéticas das populações estudadas uma vez que fenômenos de auto-imunidade são por elas influenciados ${ }^{17}$. Nisto se incluem os anticorpos antifosfolípides. Outra explicação possível é a de uma possível diferença nos substratos utilizados para a pesquisa dos autoanticorpos $^{18,19}$.

Através das variáveis clínicas estudadas, não foi possível detectar algum indício clínico de que os pacientes eram portadores de anticorpos anticardiolipina. O número de tromboses venosas profundas e de abortamentos prévios não foi diferente na população com e sem esses autoanticorpos, não servindo como um indicador da sua presença. Também a presença de livedo reticularis não foi achada com maior prevalência nos pacientes com úlceras de perna anticardiolipinas positivas. Sendo essa manifestação cutânea facilmente detectada ao exame físico, ela poderia constituir-se em indício da positividade desses anticorpos, sinalizando para a sua procura. Na série atualmente estudada apenas dois pacientes apresentaram essa forma cutânea de manifestação, não permitindo inferências a respeito da presença ou não dos auto-anticorpos, devido à baixa representatividade do achado na amostra.

Em tentativa de se identificar os portadores de úlcera de perna com anticardiolipinas através de exames laboratoriais de acesso mais fácil, procedeu-se à contagem de plaquetas. Conforme comentado anteriormente, em casos de SAF pode existir diminuição de seu número pelo consumo das mesmas durante os eventos trombóticos. Dessa maneira um número baixo de plaquetas poderia assinalar a presença do anticorpo.

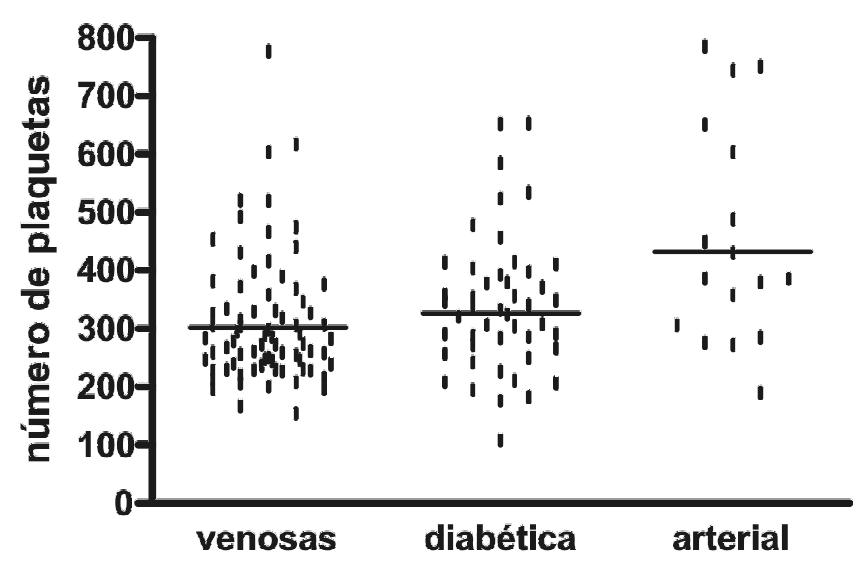

Figura 1 - Número de plaquetas nas diferentes formas de úlceras de pernas estudadas.

Arterial $X$ venosa $-p=0.004$ (Mann Whitney);

Venosa $X$ diabética=0.09 (Mann Whitney);

Diabética $X$ arterial $=p=0.05$ (Mann Whitney).

Tabela 1 - Comparação de características clínicas entre pacientes do grupo úlcera com e sem anticorpos anticardiolipinas (aCls).

\begin{tabular}{|c|c|c|c|}
\hline Variável & $\mathrm{aCl}$ positivas $\mathrm{n}=12$ & aCl negativas $n=139$ & $p$ \\
\hline Gênero (masculino:feminino) & $6: 6$ & $69: 70$ & $0,98(*)$ \\
\hline Trombose venosa prévia & $(8,3 \%)$ & $26 \quad(18,7 \%)$ & $0,69(\#)$ \\
\hline Abortamentos $(n=75)$ & $3 / 6 \quad(50 \%)$ & $26 / 69 \quad(37,6 \%)$ & $0,67(\#)$ \\
\hline Presença de livedo reticularis & 0 & $2 \quad(1,4 \%)$ & Não avaliável \\
\hline
\end{tabular}

n=número da amostra

(\#) Teste de Fisher.

(*) Qui-quadrado. 
Neste estudo constatou-se o contrário. Pacientes do grupo com úlceras de pernas demonstraram possuir maior quantidade de plaquetas do que o grupo controle, o que pode ser atribuído à trombocitose reativa ao processo inflamatório no local da úlcera ${ }^{20}$. Trombocitose em pacientes com úlcera de perna já havia sido descrita anteriormente por Goodfield ${ }^{21}$. Entretanto, esse achado não pode ser usado como argumento para alegar que não exista trombose no local da úlcera porque a ocorrência de microeventos talvez não seja suficiente para afetar o número de plaquetas circulantes. Neste aspecto, é interessante observar que, apesar de não existir diferenças entre contagens de plaquetas dos indivíduos com úlceras de pernas e sem anticardiolipinas, existem diferenças entre os números médios de plaquetas obtidos nos diferentes tipos de úlcera. Nas úlceras arteriais, nas quais não se obteve número significativo de positividade de aCls, observou-se valor mais alto, estatisticamente significante, em relação à contagem de plaquetas de pacientes com úlceras venosas e diabéticas. Esse achado favorece a possibilidade de que um aumento de consumo de plaquetas em pacientes, partindo de contagens iniciais mais altas, pode não ser facilmente percebido.

Concluindo, pode-se dizer que existe aumento de prevalência de anticorpos anticardiolipinas na população local com úlceras de pernas. Neste contexto, a presença desse auto-anticorpo não pode ser inferida pela história anterior de tromboses venosas e abortamento, presença de livedo reticularis ao exame físico ou contagens plaquetárias.

\section{A B S T R A C T}

Objective: To study the prevalence of anticardiolipin antibodies in patients with venous, diabetic and arterial leg ulcers and to verify if platelet count, previous history of venous thrombosis, obstetrical history and the finding of livedo reticularis are markers of this autoantibody positivity. Methods: 151 patients with leg ulcer (81 with venous, 50 with diabetic and 20 with arterial ulcers) and 150 controls were included. In both groups search for the presence of $\lg G$ and $\lg M$ anticardiolipin and platelet count was done. In the leg ulcer group demographic data, obstetrical history, previous history of venous thrombosis as well as presence of livedo reticularis by physical examination were pointed out. Data was grouped in contingency and frequency tables and the tests of Fisher and chi-squared were used for nominal variables and Mann Whitney and Kruskall Wallis for numerical variables. The adopted significance was of $5 \%$. Results: It was found an anticardiolipin prevalence of $7.2 \%(n=12)$ in the leg ulcer group and of $1.3 \%(n=2)$ in the control group ( $p=0.01)$. Leg ulcer patients with anticardiolipin did not differ from those without it in gender $(p=0.98)$, previous history of venous thrombosis $(p=0.69)$, previous history of abortions $(p=0.67)$ and platelet count $(p=0.67)$. Only two patients had livedo reticularis which precluded any conclusion on this data. Conclusion: There is an increased prevalence of anticardiolipin antibodies in the general population with leg ulcers. Clinical characteristics of ulcers as well as platelet count do not help in the identification of these patients.

Key words: Leg ulcer. venous insufficiency. Skin ulcer. Diabetic foot. Antibody anticardiolipin.

\section{REFERENCIAS}

1. Petri M. Clinical and management aspects of antiphospholipid antibody syndrome. In: Wallace DJ, Hahn BH, editors. Dubois' Lupus erythematosus. Philadelphia: Lippicott Willians \& Wilkins; 2007. p. 1262-97.

2. Khamashta MA, Hugues GRV. The clinical aspects of the antiphospholipid syndrome. In: Lahita RG, editor. Systemic lupus erythematosus. San Diego: Elsevier; 2004. p. 1107-23.

3. Gezer S. Antiphospholipid syndrome. Dis Mon. 2003; 49(12):696741.

4. Heilmann L, Schorch M, Hahn T, Adasz G, Schilberz K, Adiguzel C, Fareed J. Pregnancy outcome in women with antiphospholipid antibodies: report on a retrospective study. Semin Thromb Hemost. 2008; 34(8):794-802. Epub 2009 Feb 12.

5. Francès $C$, Niang $S$, Laffitte $E$, Pelletier F, Costedoat N, Piette JC. Dermatologic manifestations of the antiphospholipid syndrome: two hundred consecutive cases. Arthritis Rheum. 2005; 52(6):178593.

6. Weinstein S, Piette W. Cutaneous manifestations of antiphospholipid antibody syndrome. Hematol Oncol Clin North Am. 2008 Feb;22(1):67-77.

7. Cervera R, Piette JC, Font J, Khamashta MA, Shoenfeld Y, Camps MT et al. Antiphospholipid syndrome: clinical and immunologic manifestations and patterns of disease expression in a cohort of 1,000 patients. Arthritis Rheum. 2002; 46(4):1019-27.
8. Mackenzie RK, Ludlam CA, Ruckley CV, Allan PL, Burns P, Bradbury AW. The prevalence of thrombophilia in patients with chronic venous leg ulceration. J Vasc Surg. 2002; 35(4):718-22.

9. Alagözlü H, Bakici Z, Gültekin F, Yildirim B, Sezer H. Anticardiolipin antibody positivity in diabetic patients with and without diabetic foot. J Diabetes Complications. 2002; 16(2):172-5.

10. Culloch D. Screening for Diabetes Mellitus. In Uptodate on line, versão 16.3 de outubro de 2008. Disponível em URL: http:// www.uptodate.com/home /index.html. Acesso em novembro de 2008.

11. Grey JE, Harding KG, Enoch S. Venous and arterial leg ulcers. BMJ. 2006; 332(7537):347-50.

12. Goldberg SN, Conti-Kelly AM, Greco TP. A family study of anticardiolipin antibodies and associated clinical conditions. Am J Med. 1995; 99(5):473-9.

13. Gertner E, Lie JT. Systemic therapy with fibrinolytic agents and heparin for recalcitrant nonhealing cutaneous ulcer in the antiphospholipid syndrome. J Rheumatol. 1994; 21(11):2159-61.

14. Tishler M, Papo J, Yaron M. Skin ulcer as the presenting symptom of primary antiphospholipid syndrome - resolution with anticoagulant therapy. Clin Rheumatol. 1995; 14(1):112-4.

15. Hairston BR, Davis MD, Gibson LE, Drage LA. Treatment of livedoid vasculopathy with low-molecular-weight heparin: report of $2 \mathrm{ca}$ ses. Arch Dermatol. 2003; 139(8):987-90.

16. Magro CE, Guidolin F, Bezerra Neto F, Mesquita L, Skare TL. Livedo reticularis ulcerado em paciente com anticorpo anticardiolipina tipo IgA. An Bras Dermatol. 2005; 80(5):538-9. 
17. Hunter DJ. Gene-environment interactions in human diseases. Nat Rev Genet. 2005; 6(4):287-98.

18. Domenico Sebastiani G, Minisola G, Galeazzi M. HLA class II alleles and genetic predisposition to the antiphospholipid syndrome. Autoimmun Rev. 2003; 2(6):387-94.

19. Goldstein R, Moulds JM, Smith CD, Sengar DP. MHC studies of the primary antiphospholipid antibody syndrome and of antiphospholipid antibodies in systemic lupus erythematosus. J Rheumatol. 1996; 23(7):1173-9.

20. Santhosh-Kumar CR, Yohannan MD, Higgy KE, al-Mashhadani SA. Thrombocytosis in adults: analysis of 777 patients. J Intern Med. 1991; 229(6):493-5.

21. Goodfield MJ. A relative thrombocytosis and elevated mean platelet volume are features of gravitational disease. Br J Dermatol. 1986; 115(5):521-8.
Recebido em 05/01/2009

Aceito para publicação em 02/03/2009

Conflito de interesse: nenhum

Fonte de financiamento: nenhuma

\section{Como citar este artigo:}

Skare TL, Ribas CAP, Malafaia O, Ribas Filho JM, Nassif PAN, Nascimento MM, Pachnicki JPA. Contagem de plaquetas e caracterização clínica de úlceras de perna anticardiolipinas positivas. Rev Col Bras Cir. [periódico na Internet] 2009; 36(5). Disponível em URL: http:// www.scielo.br/rcbc

\section{Endereço para correspondência:}

Thelma L Skare

E-mail: tskare@onda.com.br 